\title{
Uveal melanoma: case report of extension through the optic nerve to the surgical margin in the orbital apex
}

\author{
JEREMY CHESS,' DANIEL M. ALBERT,' A. ROBERT BELLOWS, AND \\ RICHARD DALLOW
}

From 'Harvard Medical School, Massachusetts Eye and Ear Infirmary, Boston; 'Ophthalmic Consultants of Boston, Inc., Boston; and ${ }^{3} 8$ Hawthorne Place, Boston, Massachusetts, USA

SUMmaRY An unsuspected uveal melanoma arising in a phthisical eye extended through the optic nerve to the surgical margin in the orbital apex without involvement of other orbital structures. Step sections showed the continuous extension through the nerve. Factors likely to predispose to optic nerve extension include epithelioid cell type, large tumour size, peripapillary involvement, and glaucoma. Optic nerve extension carries the risks noted with orbital extension of intraocular tumour, but may in addition lead more directly to intracranial invasion, including a chiasmal syndrome. The role of exenteration and radiotherapy in these cases remains uncertain.

Optic nerve extension of uveal melanomas is currently a relatively uncommon occurrence. It was noted, for example, in $3.6 \%$ of the reported cases summarised by Reese' ${ }^{\prime}$ and in less than $0.6 \%$ of the extensive series reported by Wilder and Paul. ${ }^{2}$ In an earlier series optic nerve extension was seen in approximately $20 \%$ of cases.

We report a case of an unsuspected uveal melanoma in a phthisical eye which we believe is unique in its documentation by stepped sections of optic nerve extension to the orbital apex without invasion of other orbital tissues. Several previous reports ${ }^{3-7}$ have made note of this form of tumour spread but have not to our knowledge eliminated the possibility of orbital or haematogenous spread of tumour to the optic nerve in the orbital apex. This case also brings to light problems encountered in the diagnosis of unsuspected intraocular malignant melanomas and the management of extraocular spread of this tumour.

\section{Case report}

A 59-year-old white man presented in the Emergency Room at the Massachusetts Eye and Ear Infirmary on 21 November 1977. His previous ophthalmic history was reported to include the development of an inferotemporal quadrantanopsia in 1969 following a retinal vascular occlusion. Six months later he became

Correspondence to Danicl M. Albert, MD, Massachusetts Eyc and Ear Infirmary, 243 Charles Strect, Boston, MA 02114, USA. totally blind in the eye. He had been followed up by a private ophthalmologist, now deceased, for increased intraocular pressure and intermittent pain associated with iris neovascularisation.

His previous medical history included medically controlled seizures dating back to childhood and systemic hypertension. Previous reported surgery had been limited to mastoidectomies.

At the time of his first examination by one of us (A.R.B.) on 21 November 1977 visual acuity was no light perception in the right eye and 20/25 in the left with best correction. Pertinent findings were limited to the right eye. There was $3+$ conjunctival injection. The cornea was clear. A large blood clot filled the anterior chamber, and no other ocular structures could be visualised. Intraocular pressure was 29 $\mathrm{mmHg}$ OD and $16 \mathrm{mmHg}$ OS. Miotics were discontinued, and treatment with topical atropine and steroids was instituted.

The haemorrhage had not entirely cleared until 17 February 1978, at which time fluffy anterior chamber debris and a mature cataract were noted along with continued glaucoma. Inability to visualise the fundus prompted a referral for ultrasound examination on 2 March 1978.

Ultrasound examination revealed a globe 'somewhat smaller than average' with normal configuration. Debris in the anterior chamber and cataract were noted. The vitreous cavity was 'almost entirely filled with confluent moderate and low 


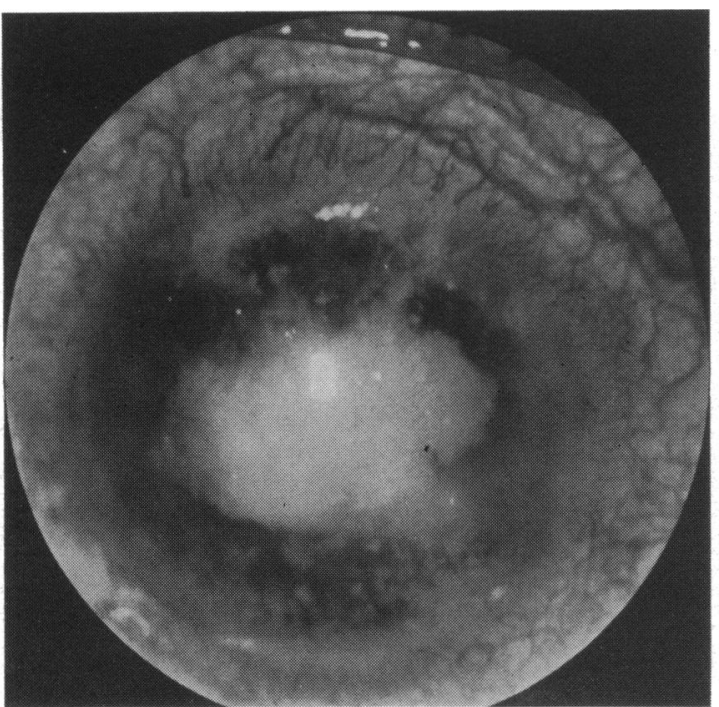

Fig. 1 External appearance of phthisical globe prior to enucleation.

density membranes.' It was felt that the findings 'probably represent very marked intraocular debris from hemorrhage or inflammation; however, retinal detachment or tumor cannot be excluded.'

In February 1979 the eye was found to be discoloured and deformed, and the intraocular pressure was too low to be measured accurately (Fig. 1). The patient was advised to undergo enucleation, but he refused. However, after continued bouts of discomfort and inflammation he consented to an enucleation. An additional ultrasound examination was performed and revealed findings interpreted as disorganized intraocular contents with the probability of organized retinal detachment. No intraocular tumor was identified.' Enucleation was performed on 21 May 1981.

Histopathological examination revealed an intraocular melanoma with tumour present at the site of transection of the optic nerve. The patient was readmitted to the hospital and examined for metastases. A physical examination, chest $x$-ray, skeletal survey, bone scan, liver and spleen scan, serum chemistry profile, and orbital computerised tomography scan failed to reveal evidence of metastatic disease. An orbital exenteration was performed. Postoperative external beam radiotherapy was administered. He received 5000 rads to the right orbit and intracranial optic nerve during a 5-week period. The left eye retained normal visual acuity and a normal visual field. However, the patient presented 17 months after enucleation with lung and liver metastases and died with widespread metastases. No post-mortem examination was performed.
GROSS PATHOLOGICAL DESCRIPTION

The deformed right eye measured $17 \times 19 \times 20 \mathrm{~mm}$. The opacified cornea measured $9 \times 10 \mathrm{~mm}$. The pupil was not visible. Minimal conjunctival and orbital tissue was attached. The optic nerve was $1 \mathrm{~mm}$ in length and the cut end appeared black. The eye was sectioned horizontally.

The globe was filled with a homogeneous, black, poorly cohesive material. The anterior chamber was obliterated, no angle structures were visible, and the iris and ciliary body could not be identified. The retina, choroid, and optic disc could not be distinguished grossly. The sclera was intact.

\section{MICROSCOPICAL DESCRIPTION}

A large diffuse uveal melanoma of mixed cell type extended from the optic nerve to the ciliary body and occupied approximately one half of the vitreous cavity. There was a predominance of spindle B cells but an average of 5 epithelioid cells per high-power field were present (Fig. 2).

The cornea showed stromal scarring; Descemet's membrane was thrown into folds. Disorganised remnants of necrotic iris were present, and the angle structures were not identifiable. The anterior chamber was filled with a thick proteinaceous material containing cholesterol crystals. The cataractous lens was dislocated anteriorly. Cholesterol crystals and red blood cells were found in the anterior vitreous. The retina was disorganised and detached. Tumour cells extended into the inner scleral lamellae and also invaded the optic nerve, extending to the site of surgical transection. Sections

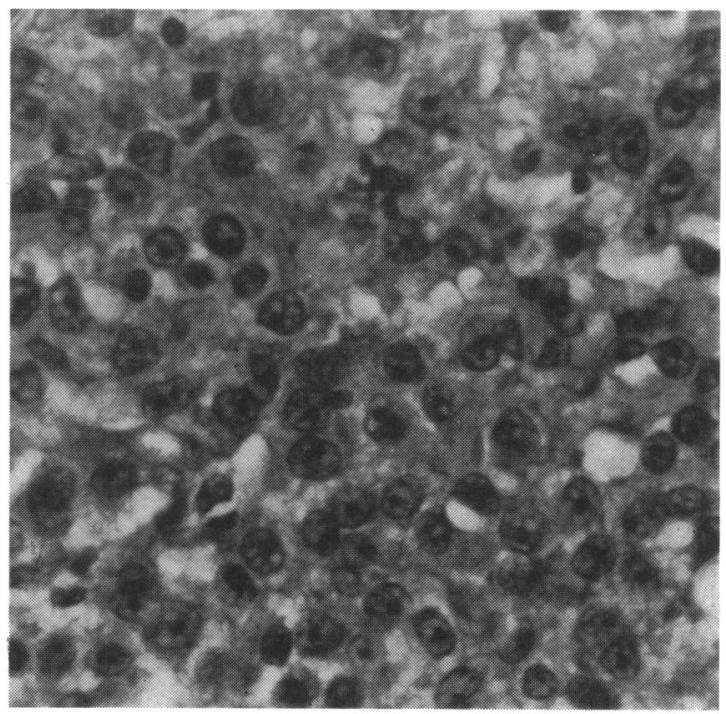

Fig. 2 Epithelioid melanoma, intraocular portion. Haematoxylin and $\operatorname{cosin}(\times 100)$. 
Fig. 3 Melanoma invading atrophic optic nerve. Haematoxylin and eosin $(\times 100)$.

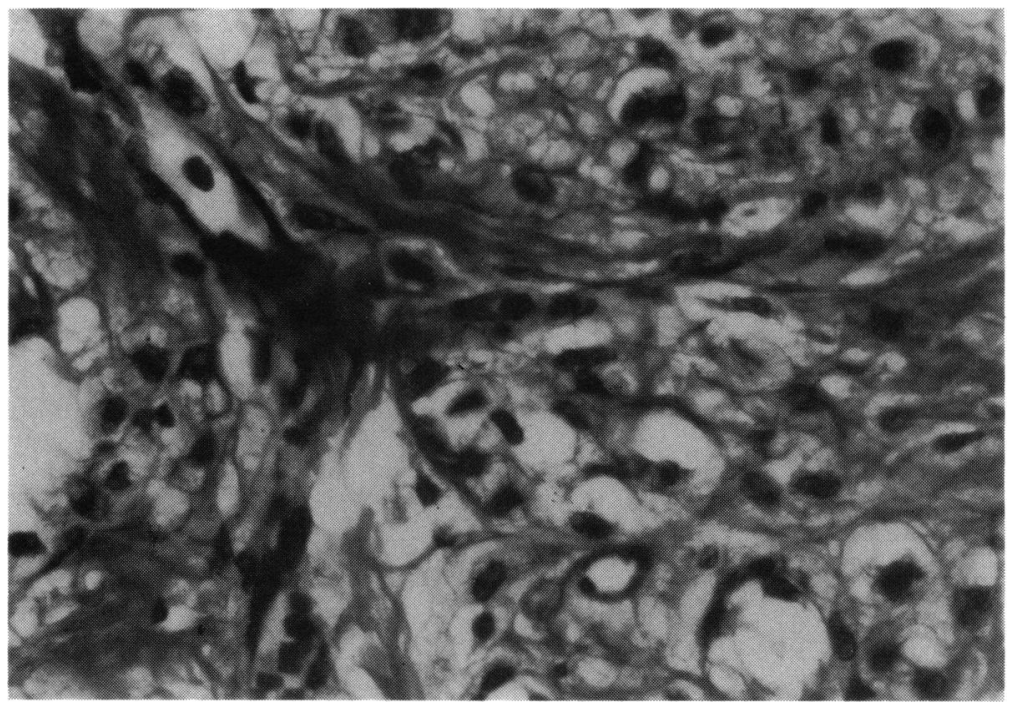

of tumour invading the optic nerve papilla were not available because of inadvertent thick sectioning of the paraffin block through this area prior to discovery of the intraocular tumour.

\section{MICROSCOPIC FINDINGS OF THE EXENTERATION SPECIMEN}

Invasion of the optic nerve by melanoma cells extended from the proximal to distal end of this specimen. Stepped sections revealed the continuity of the tumour through the nerve from the globe to the surgical margin at the level of the annulus (Fig. 3). No tumour was present in the other orbital tissues.

\section{Discussion}

The present case is of interest as an example of an uncommon form of spread of a uveal melanoma in the absence of extraocular extension through the scleral emissary canals. We showed with stepped sections of the exenterated orbital tissue that spread of tumour to the orbital apex was entirely within the optic nerve and that there has been no invasion of other orbital structures.

The possibility of intracranial invasion through the optic nerve was first suggested by Knapp ${ }^{3}$ in 1864 and illustrated in a report by Landsberg. ${ }^{4}$ Two well documented cases were reported by Terry" from our institution in 1935 in which intracranial extension along the optic nerve led to a hemianopia in the fellow eye from chiasmal involvement and in which the eventual deaths resulted from the intracranial involvement. A similar case encountered by Blodi was reported by Spencer. ${ }^{7}$
The present case is also instructive in relation to the clinical problems encountered in the management of phthisical eyes. The risk of a 'hidden' melanoma in a phthisical eye has been well documented, and $12 \%$ of histologically proved uveal melanomas were unsuspected preoperatively in the series reported by Yanoff and Zimmerman. ${ }^{8}$ There has been increased reliance on ultrasound examination to detect these tumours, but this may be difficult even in expert hands.

A number of factors noted by others to increase the likelihood of optic nerve extension were prominent features in our patient. Reese, ' Samuels, "' and Wilder and $\mathrm{Paul}^{2}$ emphasised that this form of invasion was prominent in advanced cases, often with juxtapapillary location. Shammas and Blodi." reviewed 26 cases of peripapillary melanoma with optic nerve extension and found that most were necrotic tumours with mixed or epithelioid cell type. Further, they found invasion of the retina, blindness, and secondary glaucoma in all their cases. Spencer ${ }^{7}$ commented on the possible mechanism by which glaucoma may lead to optic nerve extension. He indicated that the possible development of cavernous atrophy secondary to increased intraocular pressure might predispose the nerve to tumour invasion. A rubeotic glaucoma, presumably secondary to the reported vascular occlusion occurring some 10 years prior to enucleation, was a noted aspect of our patient's clinical course.

The prognosis for patients with optic nerve extension was noted by Shammas and Blodi" ${ }^{\text {") }}$ to be 'mainly dependent on the presence of orbital extension.' Orbital exenteration has been the most 
frequent surgical approach to this problem, but its effectiveness is controversial. Starr and Zimmerman" described the poor outcome after exenteration for orbital extension. Fourteen of their 15 patients were dead of metastases within an average period of 13 months. Subsequently Shammas and Blodi'2 found that exenteration within 8 weeks of enucleation led to a significant improvement in 5year survival rates in their 13 patients undergoing orbital exenteration. However, Affeldt et al. ${ }^{1.3}$ did not observe an improved survival rate in a series of 7 patients treated with early exenteration. Similarly, the therapeutic role of radiotherapy ${ }^{14}$ or neurosurgery in cases such as ours remains uncertain.

\section{References}

1 Reese AB. Tumors of the Eye. New York: Harper. 1951.

2 Wilder HC, Paul EV. Malignant melanoma of the choroid and ciliary body: a study of 2535 cases. Milit Surg 1951; 109: 37()-8.

3 Knapp H. A treatise on intraocular tumors from original clinical observations and anatomical investigations. Trans Cole S. New York: Wood, 1869.
4 Landsberg M. Sarcom der Choroidea schr langsamer, cigenthümlicher Verhauf. Arch Ophthalmol 1869; 15: 210-4.

5 Terry TL, Johns JP. Uveal sarcoma-malignant melanoma: statistical study of 94 cases. A $m$ J Ophthalmol 1935; 18: 9()3-13.

6 Terry TL. Malignant so-called sarcoma of uvea. Arch Ophthalmol 1940); 24: 206-14.

7 Spencer WH. Optic nerve extension of intraocular neoplasms. Am J Ophthalmol 1975; 80: 465-71.

8 Yanoff M, Zimmerman LE. Histogenesis of malignant melanomas of the uvea. II. Relationship of uveal nevi to malignant melanomas. Cancer 1967; 20: 493-507.

9 Samucls B. Study of anatomic and clinical manifestations of necrosis in 84 cases of choroidal sarcomas. Arch Ophthalmol 1934: 11: 998-1027.

10 Shammas HF, Blodi FC. Peripapillary choroidal melanomas. Arch Ophthalinol 1978; 96: 440-5.

11 Starr HJ, Zimmerman LE. Extrascleral extension of choroidal and ciliary body melanomas. Int Ophthalmol Clin 1962; 2: $369-85$

12 Shammas HF, Blodi FC. Orbital extension of choroidal and ciliary body melanomas. Arch Ophthalmol 1977; 95: 2(0)2-5.

13 Affeldt JC, Minckler DS, Azen SP, Yeh L. Prognosis in uveal melanoma with extrascleral extension. Arch Ophthalmol 1980; 98: $1975-9$

14 Char DH, Phillips RD. The potential for adjuvant radiotherapy in choroidal melanoma. Arch Ophthalmol 1982; 100: 247-8. 